Pesq. Vet. Bras. 1313-1321, novembro 2017 DOI: $10.1590 / \mathrm{S} 0100-736 X 2017001100019$

\title{
Doenças micóticas em gatos no Rio Grande do Sul ${ }^{1}$
}

\author{
Neusa B. Castro², Veronica M. Rolim², Lismara C. do Nascimento ${ }^{2}$, Amaro F.V. Silveira², \\ Fernando F. Argenta ${ }^{2}$, Laerte Ferreiro ${ }^{3}$, David Driemeier ${ }^{2}$ e Luciana Sonne ${ }^{2 *}$
}

\begin{abstract}
Castro N.B., Rolim V.M., Nascimento L.C., Silveira A.F.V., Argenta F.F., Ferreiro L., Driemeier D. \& Sonne L. 2017. [Fungal diseases in cats in Rio Grande do Sul, Brazil.] Doenças micóticas em gatos no Rio Grande do Sul. Pesquisa Veterinária Brasileira 37(11):1313-1321. Setor de Patologia Veterinária, Faculdade de Veterinária, Universidade Federal do Rio Grande do Sul, Av. Bento Gonçalves 9090, Prédio 42505, Porto Alegre, RS 91540-000, Brazil. E-mail: lusonne@yahoo.com.br

Fungal disease is included in the differential diagnosis of a wide range of disorders in cats. At the Department of Veterinary Pathology of Federal University Federal of Rio Grande do Sul (SPV-UFRGS), evaluation of records data of cats from January 2005 to December 2015 were examined. A total of 1,274 necropsy have been reviewed from which 17 cases of fungal infection was revealed accounting for $1.33 \%$, and a total of 2,615 biopsies have been reviewed from which 59 cases of fungal infection was revealed, accounting for $2.25 \%$. We retrospectively analyzed the gross and microscopic findings and the yield of additional diagnostic approaches employed. Sporotrichosis was the most common diagnosis with 34 cases found in biopsy and five necropsies. Cryptococcosis obtained six diagnoses through necropsy and 13 through biopsy. Dermatophytic pseudomycetoma was found in five cases in biopsy and two necropsies. Histoplasmosis diagnosis was obtained in one necropsy and two biopsies. Aspergillosis had two cases diagnosed in necropsy. Candidiase and phaeo-hyphomycosis accounted for one case each. In four occasions, it was not possible to identify the agent involved and the diagnosis was made regarding the morphological changes: fungal dermatitis, fungal enteritis, mycotic rhinitis, and fungal dermatitis and osteomyelitis. In this study, sporotrichosis could be identified as the most frequent diagnosis of fungal disease in cats, followed by cryptococcosis and dermatophytic pseudomycetoma.
\end{abstract}

INDEX TERMS: Fungal diseases, cats, biopsy, necropsy, histology.

RESUMO.- As enfermidades fúngicas são diagnósticos diferenciais de diversas morbidades de caráter infeccioso, degenerativo ou proliferativo neoplásico, principalmente em gatos, que é a espécie mais suscetível a estas. Este trabalho descreve os achados anatomopatológicos de doenças fúngicas em gatos no período de janeiro de 2005 a dezembro de 2015 pelo SPV-UFRGS. Foram revisados 1.274 protocolos de necropsia e encontrou-se 17 casos de micoses, correspondendo a 1,33\% dos diagnósticos. Quanto às amostras pro-

\footnotetext{
${ }^{1}$ Recebido em 9 de agosto de 2016.

Aceito para publicação em 27 de janeiro de 2017

Parte da Dissertação de Mestrado do primeiro autor.

${ }^{2}$ Setor de Patologia Veterinária, Faculdade de Veterinária, Universidade Federal do Rio Grande do Sul (UFRGS), Av. Bento Gonçalves 9090, Prédio 42505, Porto Alegre, RS 91540-000, Brasil. *Autor para correspondência: lusonne@yahoo.com.br

${ }^{3}$ Laboratório de Micologia, Faculdade de Veterinária, UFRGS, Av. Bento Gonçalves 9090, Porto Alegre, RS 91540-000, Brasil.
}

venientes de biopsias, foram verificados 2.615 protocolos e detectou-se 59 casos de doenças fúngicas, totalizando 2,25\% dos diagnósticos, sendo revisados seus achados macroscópicos, microscópicos, colorações especiais e cultivo micológico. O principal diagnóstico encontrado foi esporotricose com 34 casos de biópsia e cinco de necropsia. Criptococose obteve seis diagnósticos na necropsia e 13 na biópsia. 0 pseudomicetoma dermatofítico possui cinco casos de biópsia e dois de necropsia. Histoplasmose obteve um diagnóstico na necropsia e dois na biópsia. Aspergilose teve dois casos diagnosticados na necropsia. Candidíase e feo-hifomicose obtiveram um caso cada. Em quatro ocasiões, não se pode identificar o agente envolvido na lesão e foram classificados conforme a alteração morfológica em: dermatite fúngica, enterite fúngica, rinite micótica e dermatite e osteomielite fúngica. Através deste trabalho, pode-se identificar que a esporotricose foi o diagnóstico de doença fúngica mais frequente em felinos, seguido da criptococose e pseudomicetoma dermatofítico. 
TERMOS DE INDEXAÇÃO: Doenças fúngicas, gatos, biópsia, necropsia, histologia.

\section{INTRODUÇÃO}

Os fungos são seres eucarióticos, não possuem clorofila e não possuem celulose na sua parede celular. Encontram-se dispersos nos vegetais, solo, água, nos animais e humanos (Gompertz et al. 2008). Existem em torno de 800.000 espécies conhecidas de fungos, destes, 400 são capazes de causar doença em humanos e animais (Quinn et al. 2011).

É sabido que os gatos são altamente suscetíveis a diversas infecções fúngicas, e que muitas dessas doenças são importantes zoonoses, tais como dermatofitose (Outerbridge 2006) e esporotricose (Schubach et al. 2015).

Estima-se que animais de companhia possam transmitir de 30 a 40 doenças zoonóticas (Moriello 2003) e que as infecções fúngicas sistêmicas sejam as principais causas de morbidade e mortalidade em pessoas imunodeprimidas (Sipsas \& Kontoyiannis 2008).

As infecções micóticas podem ser classificadas quanto ao local da lesão em cutâneas, subcutâneas (ou de implantação) e sistêmicas (Quinn et al. 2011). Os sinais clínicos são variados, muitas vezes inespecíficos e dependem do órgão atingido.

Os meios diagnósticos mais comuns para doenças micóticas incluem: sorologia, identificação do agente através dos exames citopatológicos ou histopatológicos, cultura e através de técnicas moleculares (Dial 2007). Para um diagnóstico correto, o ideal é a associação de sinais clínicos com os achados em exames subsidiários ao diagnóstico (Dial 2007).

0 objetivo do trabalho foi realizar um estudo retrospectivo das principais morbidades fúngicas em felinos domésticos diagnosticados através de exames citopatológicos, histopatológicos e necropsias no Setor de Patologia Veterinária da Universidade Federal do Rio Grande do Sul (SPV-UFRGS).

\section{MATERIAL E MÉTODOS}

Como critérios de inclusão foram identificados os casos de infecções micóticas em gatos domésticos a partir dos registros de necropsias e biópsias no período de janeiro de 2005 a dezembro de 2015. De todos os animais incluídos foram avaliados os dados clínicos e epidemiológicos, os achados macroscópicos, descrições citopatológicas e histopatológicas. As amostras provenientes de necropsias foram processadas rotineiramente para histologia e corados com hematoxilina e eosina (HE) e colorações especiais de ácido periódico de Schiff (PAS) e metenamina prata de Grocott conforme descrito por Arrington (1992).

Lâminas citopatológicas, quando necessário, foram coradas por PAS. 0 diagnóstico das micoses foi obtido através das características histológicas/citológicas e histoquímicas dos agentes. Alguns espécimes provenientes de necropsia foram enviados ao Laboratório de Micologia da UFRGS para cultivo micológico.

É importante destacar que a maioria dos diagnósticos obtidos nesse estudo foram baseados nos achados microscópicos dos agentes e através de técnicas histoquímicas, visto que a maioria das amostras já foi recebida fixada em formalina a 10\%, ou, durante a necropsia, não se suspeitou de doença micótica pelas alterações visualizadas ou apresentava lesões inespecíficas, impossibilitando a coleta para cultivo fúngico.

\section{RESULTADOS}

No período de 2005 a 2015, foram enviados 1.274 gatos para necropsia. 0 total de diagnósticos que corresponderam a doenças infecciosas foi de 243 casos, destes, 17 foram de doenças fúngicas, totalizando $1,33 \%$ de diagnósticos totais de gatos no período e $7 \%$ dos diagnósticos de doenças infecciosas. Quanto às amostras provenientes de biópsias, foram recebidos 2.615 materiais, destes, 59 corresponderam a doenças micóticas, o que representou 2,25\% do total de diagnósticos nessa espécie. Das 59 amostras de biópsias, 37 eram provenientes de exames histopatológicos, 21 eram citopatológicos e um possuía histopatológico e citopatológico.

Dentre os 76 gatos com infecções micóticas, 43 (56,57\%) foram machos. Os animais sem raça definida (SRD) representaram $69,74 \%$, e os demais correspondiam às raças Persa $(11,84 \%)$, Siamês $(9,21 \%)$, Himalaio $(2,63 \%)$ e Maine Conn $(1,32 \%)$. Em 8,39\% não tinham a raça informada nos protocolos. As idades dos animais avaliados variaram de 8 meses a 16 anos. 0 diagnóstico das micoses foi obtido através das características histológicas/citológicas e histoquímicas dos agentes. As enfermidades fúngicas de felinos obtidas no estudo estão apresentadas no Quadro 1.

\section{Quadro 1. Doenças fúngicas de gatos diagnosticados no período de 2005-2015 no Setor de Patologia Veterinária da UFRGS}

\begin{tabular}{lcccc}
\hline \multicolumn{1}{c}{ Diagnóstico } & \multicolumn{2}{c}{$\mathrm{AP}$} & \multicolumn{2}{c}{$\mathrm{N}$} \\
\cline { 2 - 5 } & $\mathrm{n}$ & $(\%)$ & $\mathrm{n}$ & $(\%)$ \\
\hline Esporotricose & 34 & 57,63 & 5 & 29,41 \\
Criptococose & 13 & 22,03 & 6 & 35,29 \\
Pseudomicetoma & 5 & 8,50 & 2 & 11,76 \\
Histoplasmose & 2 & 3,39 & 1 & 5,89 \\
Aspergilose & 0 & 0 & 2 & 11,76 \\
Candidose & 1 & 1,69 & 0 & 0 \\
Feo-hifomicose & 1 & 1,69 & 0 & 0 \\
Dermatite fúngica & 1 & 1,69 & 0 & 0 \\
Enterite fúngica & 0 & 0 & 1 & 5,89 \\
Rinite micótica & 1 & 1,69 & 0 & 0 \\
Dermatite e osteomielite fúngica & 1 & 1,69 & 0 & 0 \\
Total & 59 & 100 & 17 & 100
\end{tabular}

$\overline{\mathrm{AP}}=$ anatomopatológicos (biópsias), $\mathrm{N}=$ necropsias.

\section{Esporotricose}

Foram diagnosticados cinco casos de esporotricose em gatos que foram enviados à necropsia, dois já possuíam diagnóstico prévio de esporotricose e em um havia suspeita da doença. Todos os animais possuíam múltiplas lesões de pele no exame macroscópico que variavam de alopécicas, ulcerativas encimadas por crostas, principalmente na superfície externa dos pavilhões auriculares, face, ponte ou espelho nasal e membros (Fig.1A). Por vezes essas lesões eram nodulares e firmes. Um gato apresentou secreção brancacenta na narina devido a lesão que ocupava a região da concha nasal direita. Em outro animal foi observado aumento de linfonodos mandibulares, axilares e cervical superficial (Fig.1B). Em três animais foi possível realizar o isolamento do agente, o qual foi identificado como complexo Sporothrix schenckii.

Os achados microscópicos consistiam em inflamação piogranulomatosa acentuada na derme, normalmente as- 


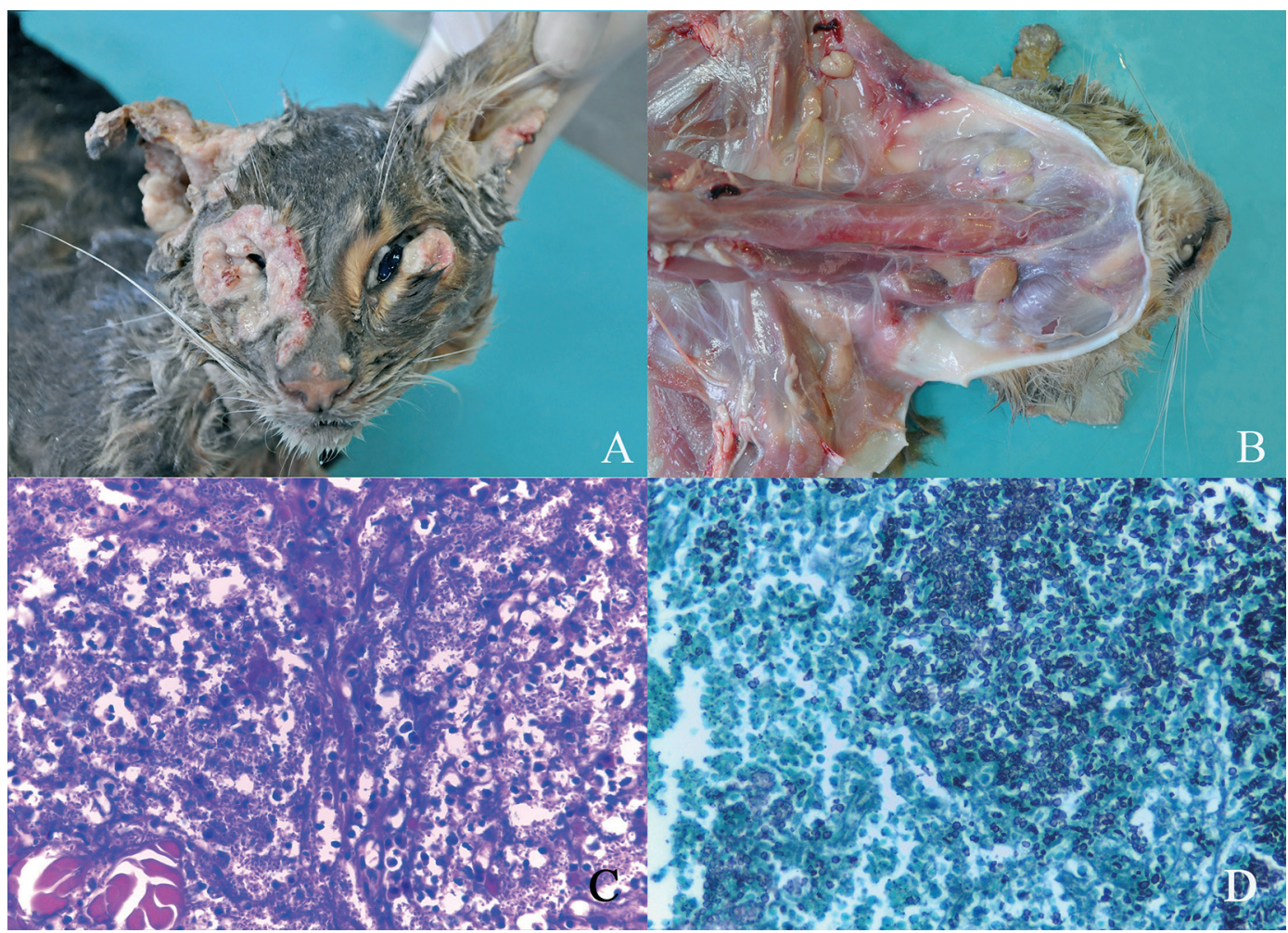

Fig.1 Esporotricose felina. (A) Gato apresentando múltiplas lesões ulceradas na pele da face e pavilhões auriculares. (B) Aumento de linfonodos mandibulares, cervicais superficiais e axilares. (C) Corte histológico de pele demonstrando infiltrado inflamatório acentuado piogranulomatoso e inúmeras estruturas leveduriformes alongadas de coloração eosinofílica. HE, obj.40x. (D) Corte histológico de linfonodo, no qual se observa grande quantidade de estruturas leveduriformes alongadas, fortemente coradas em preto, coloração de Grocott, obj.40x.

sociada também com ulceração da epiderme. Em todos os casos havia grande quantidade de leveduras, que possuíam aproximadamente de 5 a $9 \mu \mathrm{m}$ de comprimento por 2 a $5 \mu \mathrm{m}$ de largura e estavam no interior de macrófagos ou livres no interstício (Fig.1C). Em um caso, havia infiltrado inflamatório piogranulomatoso com leveduras na cavidade nasal e linfonodo mandibular. Em outro animal, as leveduras estavam presentes nos linfonodos mandibulares, cervical superficial e axilar, associado à necrose tecidual e inflamação piogranulomatosa.

Dos materiais enviados para biópsia, foram identificados 34 casos de esporotricose. Destes, 16 eram exames citopatológicos e 18 eram exames histopatológicos. Foi informada a suspeita clínica em 16 casos, em dez suspeitou-se de esporotricose, nos demais, a suspeita foi de criptococose, alguma doença fúngica e de carcinoma de células escamosas. Dentre os 34 casos de biópsia, 10 eram provenientes de municípios que se localizavam no litoral do Estado do Rio Grande do Sul. Os sinais clínicos informados revelavam lesões de pele, normalmente múltiplas e ulceradas, que se localizavam nos membros, face, espelho nasal e pavilhão auricular. Em um caso foi informado que o proprietário foi arranhado por um animal doente e, desde então, apresentou aumento de linfonodos superficiais. Esse mesmo animal convivia com outros gatos e muitos deles apresentavam lesões de pele semelhantes.

As lesões histológicas em 32 animais caracterizavam-se por infiltrado inflamatório acentuado de macrófagos, linfócitos e neutrófilos e em um caso também havia células gigantes multinucleadas. Em dois gatos, a inflamação era predominantemente de neutrófilos. Em todas as amostras, as leveduras compatíveis com S. schenckii estavam presentes em grande quantidade, por vezes no interior de macrófagos ou dispersas no tecido adjacente. Estas eram alongadas, com 5 a $9 \mu \mathrm{m}$ de comprimento por 3 a $5 \mu \mathrm{m}$ de largura com um centro basofílico e um halo claro.

As leveduras foram fortemente positivas nas colorações especiais de PAS e Grocott (Fig.1D).

Em um caso foi possível realizar o isolamento fúngico, o qual foi identificado como Sporothrix schenckii.

\section{Criptococose}

Foram diagnosticados seis casos de criptococose em gatos que foram submetidos à necropsia. Os sinais clínicos foram relatados em três animais. Em dois casos descreveram-se sinais clínicos neurológicos de incoordenação, midríase, ausência de reflexo pupilar e ameaça. No outro caso, foi relatado anorexia, apatia e aumento de linfonodos poplíteos e mandibulares. Como achados macroscópicos observou-se que um gato apresentava secreção nasal purulenta que se estendia até o seio frontal e pulmões com pequenos pontos brancos. Outro animal possuía lesões ulceradas na comissura labial, com aumento dos linfonodos (mandibulares, poplíteos, mesentéricos, ilíacos e axilares) e áreas esbranquiçadas multifocais de 0,1 a $0,5 \mathrm{~cm}$ no fígado. Um felino apresentou fezes ressecadas, com distensão da bexiga e diminuição da consistência da medula espinhal em toda sua extensão. Lesões ulcerativas no espelho nasal, 


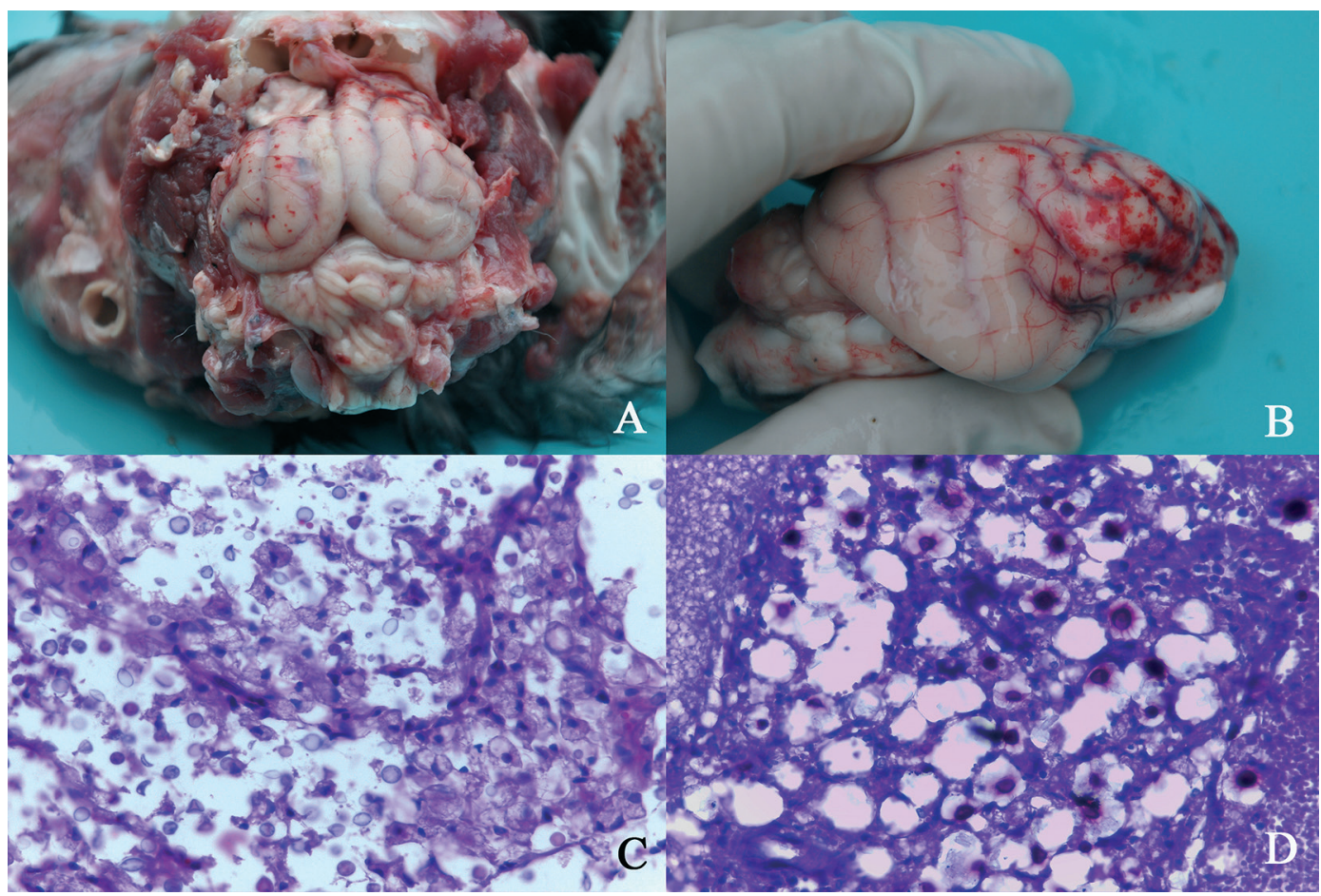

Fig.2 Criptococose felina. (A) Encéfalo com conificação do cerebelo e múltiplas petéquias no córtex. (B) Encéfalo com múltiplas petéquias no córtex frontal. (C) Corte histológico de encéfalo demonstrando discreto infiltrado inflamatório de linfócitos e macrófagos e grande quantidade de leveduras arredondadas a ovoides levemente basofílicas, coloração de HE, obj.40x. (D) Encéfalo com grande quantidade de leveduras arredondadas a ovóides fortemente coradas em rosa, algumas delas demonstram também leve marcação da cápsula, que se mostra radiada, coloração de PAS, obj.40x.

face e pavilhões auriculares foram identificados em um caso. Dois felinos exibiam alterações no encéfalo. Um deles apresentava múltiplas petéquias corticais e conificação do cerebelo (Fig.2A e 2B); já o outro exibia material de coloração esbranquiçada e aspecto gelatinoso.

$\mathrm{Na}$ microscopia foi identificado abundante quantidade de estruturas arredondadas a ovoides, de aproximadamente $10 \mu \mathrm{m}$ envoltas por grande halo pouco corado, normalmente associado a infiltrado inflamatório discreto de linfócitos e macrófagos (Fig.2C). Em três animais o agente foi identificado no cérebro, em um deles foi observado os micro-organismos no parênquima e na meninge da medula espinhal, além do encéfalo, associado à malacia, gliose e astrócitos gemistocíticos. Em dois gatos o agente foi identificado também no pulmão. Em dois animais o micro-organismo foi visualizado na pele, sendo que um deles também apresentou a levedura no linfonodo e o outro no globo ocular.

Nas amostras enviadas para biópsia foram diagnosticados 13 casos de criptococose, destes, dez eram histopatológicos e três citopatológicos. Foi informada a suspeita clínica em oito animais, em três suspeitou-se de neoplasia, em outros três animais ocorreu suspeita de doença fúngica (criptococose/esporotricose), em um caso suspeitou-se de infecção fúngica ou micobactéria e em outro de sarcoma ocular.

Os sinais clínicos em oito gatos possuíam alterações cutâneas, como nódulos e áreas ulceradas e exsudação serosanguinolenta. Em dois felinos foi relatado massa na narina e em um caso massa entre os dentes.
Na microscopia, a inflamação observada era composta de macrófagos, linfócitos e neutrófilos, e variou de discreta a acentuada. As leveduras estavam presentes em grande quantidade em oito casos e em cinco em pequena quantidade. Os micro-organismos eram arredondados a ovais, com aproximadamente $10 \mu \mathrm{m}$ de diâmetro, com centro levemente basofílico circundado por um grande halo claro que não se corava com o HE.

Na coloração de PAS, o corpo celular da levedura se corou fortemente de rosa e algumas delas obtiveram pequena marcação da cápsula, que se mostrou radiada (Fig.2D). Na coloração de Grocott a célula da levedura se corou fortemente de preto.

\section{Pseudomicetoma}

Foram diagnosticados dois casos de pseudomicetoma em gatos da raça Persa nos exames de necropsia. 0 primeiro animal possuía histórico de dermatofitose generalizada. 0 histórico do segundo animal informou que este se apresentava com fecaloma e não se alimentava sozinho. A lesão macroscópica do primeiro, consistia de uma área alopécica e escamas na região dorsal de aproximadamente $4 \mathrm{~cm}$. $\mathrm{Na}$ necropsia do segundo gato foi observado fecaloma no intestino grosso, tumor esbranquiçado granular medindo $6,0 \times 3,5 \times 2,8 \mathrm{~cm}$ no coto uterino, parede vesical e ureter direito, e hidronefrose com conteúdo purulento no rim direito. Ao corte, a bexiga apresentava área focalmente extensa avermelhada na mucosa. 0 exame microscópico revelou áreas multifocais com miríades fúngicas envoltas em material eosinofílico amorfo, fenômeno de Splendore-Hoeppli, 


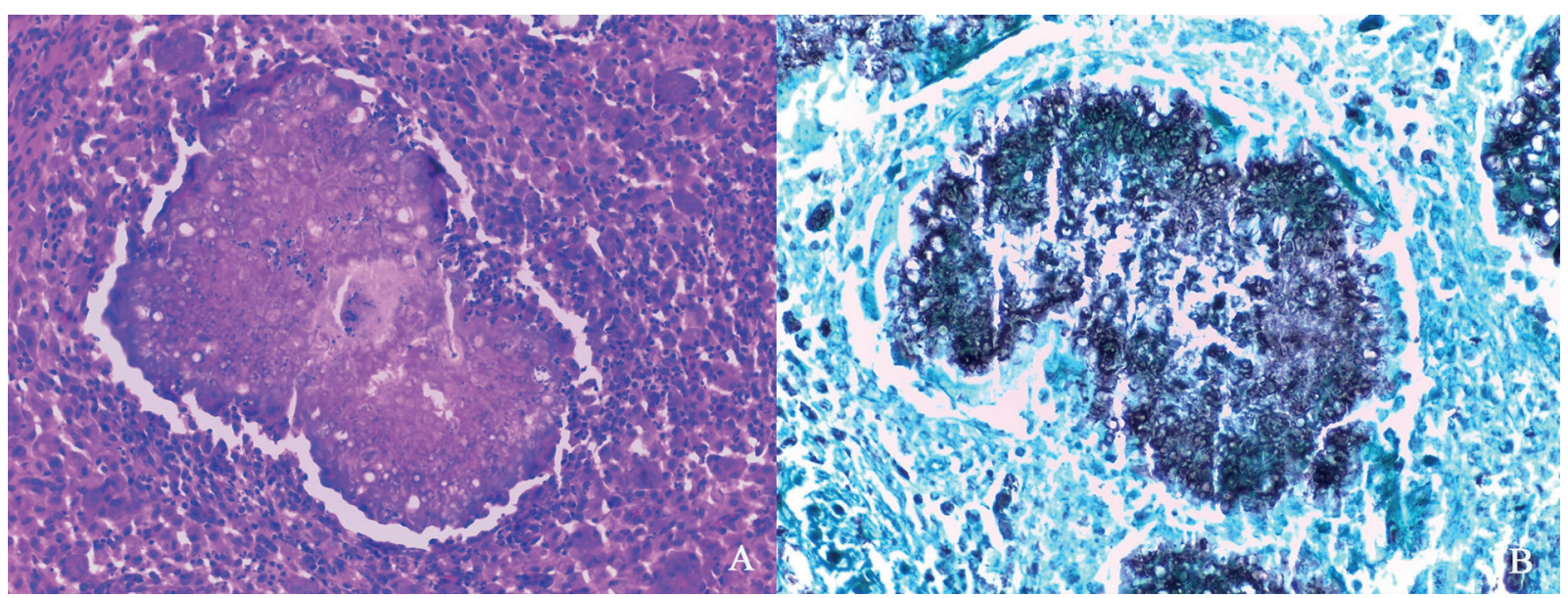

Fig.3 Pseudomicetoma dermatofítico felino. (A) Corte histológico de pele, com pseudomicetoma dermatofítico, no qual se observa área central com inúmeras imagens negativas fúngicas e material eosinofílico amorfo (fenômeno de Splendore-Hoeppli), há também acentuado infiltrado inflamatório de neutrófilos, macrófagos e células gigantes multinucleadas. HE, obj.20x. (B) Corte histológico de pele, onde se visualiza áreas multifocais com intensa marcação em preto de estruturas fúngicas, coloração de Grocott, obj.20x.

circundados por infiltrado inflamatório de neutrófilos, macrófagos e células gigantes multinucleadas (Fig.3A). Um fragmento do nódulo foi encaminhado para cultura fúngica, de onde foi isolado Microsporum canis.

Entre as amostras de biopsias, diagnosticou-se cinco casos de pseudomicetoma. Destes, quatro eram histopatológicos e um citopatológico. Quatro amostras pertenciam a gatos da raça Persa e uma era da raça Himalaia. Em três animais foram relatadas lesões tumorais cutâneas, isoladas a coalescentes com consistência variável. Em outro animal foi mencionado uma massa na região caudal da bexiga que estava aderida ao canal inguinal esquerdo. 0 exame microscópico demonstrou áreas multifocais compostas de imagens negativas fúngicas irregulares e com dilatações, em meio a material eosinofílico amorfo, caracterizando o fenômeno de Splendore-Hoeppli. Ao redor desse material era possível observar grande quantidade de infiltrado inflamatório composto de macrófagos epitelioides, neutrófilos e células gigantes multinucleadas.

Nas colorações especiais de PAS e Grocott, as estruturas fúngicas foram evidenciadas, corando-se fortemente de rosa e preto respectivamente (Fig.3B).

\section{Histoplasmose}

Um caso de histoplasmose em gatos foi diagnosticado na necropsia. Este tinha histórico clínico do animal informava linfonodomegalia generalizada e rarefação óssea no membro torácico esquerdo. Durante a necropsia foi observado aumento generalizado de linfonodos (Fig.4A), que se apresentavam macios, brancacentos e que ao corte fluía material liquefeito branco. No membro torácico esquerdo foi visualizado aumento de volume na região rádio-ulnar, que ao corte possuía material purulento e a musculatura adjacente se apresentava brancacenta (Fig.4B). Esplenomegalia com aspecto multinodular e hepatomegalia também foram observados. Os pulmões não estavam colapsados e tinham aspecto brilhante.

$\mathrm{Na}$ avaliação histopatológica dos linfonodos, rádio-ulna, meninge do encéfalo, intestino, baço, pulmão, adrenal, fíga- do e glândula da terceira pálpebra foi observado um acentuado infiltrado inflamatório composto por macrófagos com múltiplas estruturas leveduriformes arredondadas de aproximadamente $5 \mu \mathrm{m}$ de diâmetro no seu interior. Foi visualizada também, pequena quantidade de células gigantes multinucleadas e necrose tecidual no tecido muscular adjacente a rádio-ulna.

Entre os casos enviados para biópsias, foram encontrados dois diagnósticos de histoplasmose, um a partir de exame citopatológico e um a partir de histopatologia. Um dos gatos possuía múltiplos nódulos tegumentares e linfonodos mandibulares aumentados. 0 outro animal apresentava diversas lesões cutâneas na região torácica ventral. $\mathrm{Na}$ avaliação histopatológica foi observada inflamação acentuada, composta por macrófagos, linfócitos, neutrófilos e plasmócitos, além de estruturas arredondadas com aproximadamente $5 \mu \mathrm{m}$ de diâmetro predominantemente no interior de macrófagos (Fig.4C).

Nas colorações especiais de PAS e Grocott as leveduras se coraram fortemente (Fig.4D).

\section{Aspergilose}

Dois casos de aspergilose em gatos foram diagnosticados a partir da necropsia. Ambos possuíam histórico de diabetes mellitus. Na necropsia do primeiro gato foi observado aumento de linfonodos mesentéricos e o brônquio do lobo cranial esquerdo do pulmão estava obstruído por material escuro e pastoso. Foi enviado para isolamento micológico uma amostra desse material pastoso e houve crescimento de Aspergillus niger. No segundo animal, foi encontrado na necropsia, material enegrecido friável, além de líquido viscoso amarelado na bifurcação da traqueia. Na histologia, de ambos os gatos, foi identificado, no pulmão, grande quantidade de hifas septadas no interior de brônquios e bronquíolos. No interior de brônquios foram visualizados inúmeros conidióforos com fiálides e numerosos conídeos. Também foi observada necrose do epitélio de brônquios com infiltrado inflamatório composto por neutrófilos. No segundo animal, havia também 


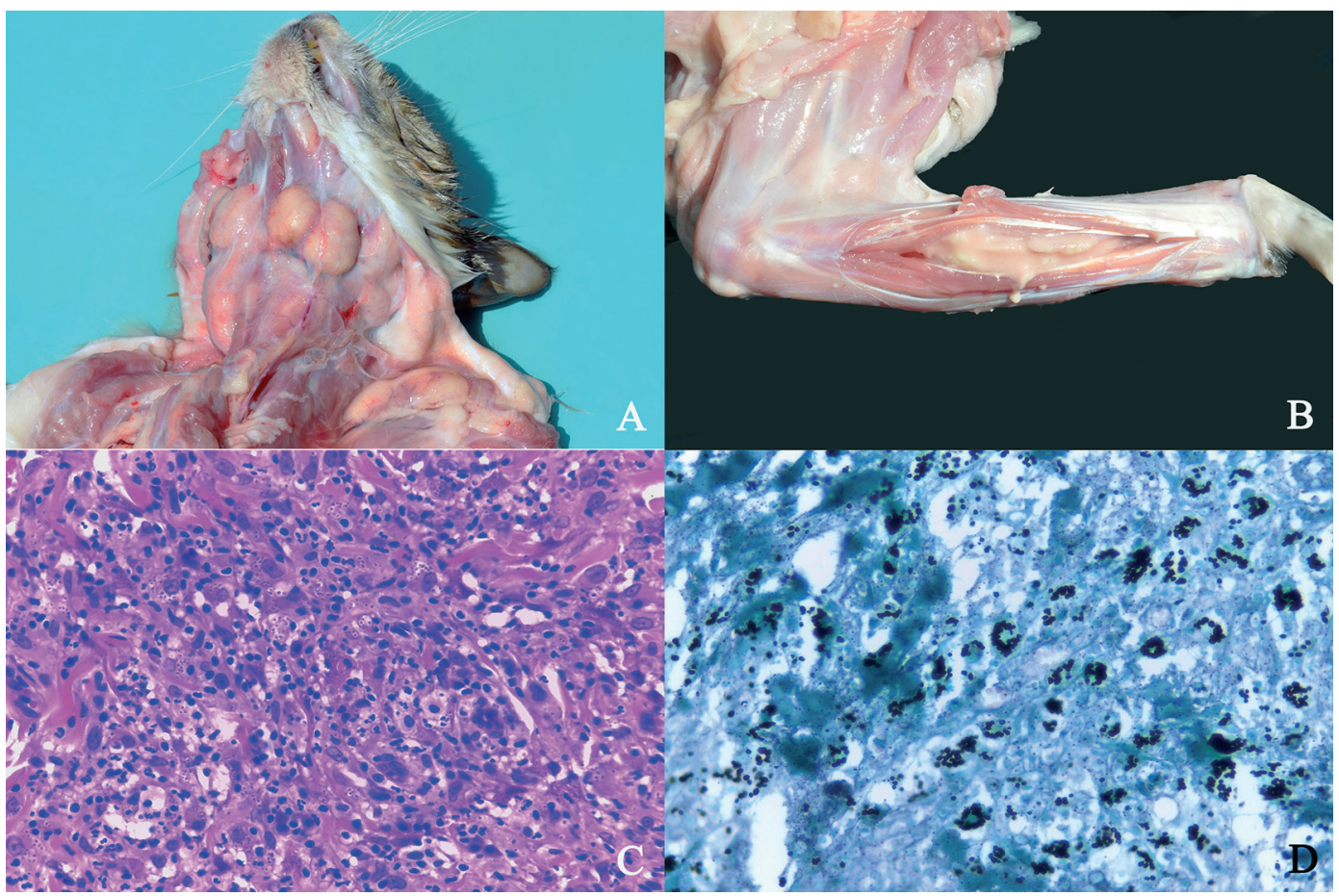

Fig.4 Histoplasmose felina. (A) Aumento acentuado de linfonodos mandibulares e cervicais superficiais. (B) Membro torácico esquerdo com material purulento fluindo ao corte da musculatura. (C) Corte histológico de pele apresentando infiltrado inflamatório difuso acentuado de neutrófilos, macrófagos, linfócitos e plasmócitos e inúmeras leveduras arredondadas predominantemente no interior de macrófagos. HE, obj.40x. (D) Corte histológico de pele com inúmeras leveduras arredondas, predominantemente no interior de macrófagos, fortemente coradas em preto, coloração de Grocott, obj.40x.

na traqueia, intenso infiltrado inflamatório constituído por linfócitos, plasmócitos e neutrófilos, além de necrose do epitélio respiratório. No interior de grandes vasos do tálamo e mesencéfalo, observou-se grande quantidade de hifas septadas, inúmeros conidióforos com fiálides e conídeos.

Nas colorações especiais de PAS e Grocott as hifas septadas, os conidióforos com as fiálides e os conídeos ficaram fortemente coradas.

\section{Candidose}

Foi encontrado um diagnóstico de candidíase dentre as amostras enviadas para biópsia. 0 animal apresentava sinais clínicos de vômito crônico, gastrite e esofagite e foi enviado um fragmento da mucosa do estômago para análise histopatológica que demostrou necrose da mucosa gástrica e hifas e leveduras de Candida sp. que se coraram fortemente nas colorações de PAS e Grocott.

\section{Feo-hifomicose}

Um caso de feo-hifomicose foi diagnosticado entre as amostras enviadas para biópsia. 0 histórico clínico informava que o animal possuía um nódulo cutâneo no membro torácico esquerdo na região interdigital, com evolução de um mês. Observou-se pela microscopia inflamação piogranulomatosa, com estruturas leveduriformes únicas ou múltiplas de coloração acastanhada no interior de macrófagos. Essas variavam de 3 a $5 \mu \mathrm{m}$ de comprimento e $3 \mu \mathrm{m}$ de largura. Nas colorações especiais de PAS e Grocott essas estruturas foram fortemente coradas.

\section{Dermatite fúngica}

Foi diagnosticado um caso de dermatite fúngica em um gato, proveniente de material de biópsia. A suspeita clínica informada era de esporotricose. 0 exame histológico revelou infiltrado inflamatório na pele, composto por neutrófilos, macrófagos, células epitelioides, células gigantes multinucleadas e plasmócitos. Havia raras estruturas leveduriformes arredondadas, que variavam de 8 a $25 \mu \mathrm{m}$ de diâmetro com citoplasma basofílico e cápsula não corada pelo HE. Nas colorações especiais de Grocott e PAS, a cápsula foi evidenciada se mostrando dupla. Não foi possível realizar outros exames complementares.

\section{Gastrenterite fúngica}

Foi diagnosticado um caso de enterite fúngica através do exame de necropsia. 0 animal possuía histórico de êmese e emagrecimento com evolução de cinco meses, o qual houve suspeita de neoplasia intestinal após exame ultrassonográfico. Na necropsia, observou-se o omento aderido à região do piloro, estômago com massa esbranquiçada invadindo a região do piloro e ulceração da mucosa, linfonodo gástrico aumentado, pulmões com múltiplos pontos brancos e áreas de consolidações. A microscopia do intestino delgado demonstrou áreas de necrose da mucosa com infiltrado inflamatório acentuado de neutrófilos, associado a áreas de proliferação de tecido conjuntivo (tecido de granulação). Em meio a essas áreas, observou-se pequena quantidade de estruturas fúngicas. Outros exames adicionais não foram realizados para determinar $o$ agente. 


\section{Rinite micótica}

Um caso de rinite micótica foi encontrado entre os diagnósticos de biópsias de gatos. 0 animal apresentava aumento da narina há aproximadamente um ano. Na microscopia, havia infiltrado inflamatório piogranulomatoso acentuado com escassas estruturas fúngicas.

\section{Dermatite e osteomielite fúngica}

Um caso de dermatite e osteomielite fúngica foi diagnosticado na análise de material coletado por biópsia. $\mathrm{Na}$ macroscopia, o membro enviado apresentava aumento de volume nas falanges com conteúdo mole e avermelhado ao corte. No exame histopatológico, a derme apresentava extensas áreas de necrose, com infiltrado inflamatório composto de neutrófilos, macrófagos, linfócitos e ocasionais células gigantes multinucleadas. No interior de macrófagos e células gigantes multinucleadas, era possível visualizar estruturas não coradas compatíveis com hifas fúngicas septadas. As hifas variavam de 10 a $70 \mu \mathrm{m}$ de comprimento por 2,5 a 3,5 $\mu \mathrm{m}$ de largura. Também havia debris necróticos e infiltrado inflamatório de linfócitos nas trabéculas ósseas. Na coloração de Grocott, as hifas se coraram fortemente.

\section{DISCUSSÃO}

As doenças micóticas representaram 7\% das doenças infecciosas avaliadas nas necropsias no período estudado. Embora tenha apresentado um baixo número de casos, um estudo semelhante diagnosticou um percentual menor, de 0,084\% de diagnósticos de doenças fúngicas em gatos em um período de 20 anos entre todos os diagnósticos nessa espécie (Galiza et al. 2014). Diversos fatores predispõem o surgimento de doenças fúngicas, como animais em tratamento oncológico, diabéticos, endocrinopatias e agentes virais que ocasionam imunossupressão (Bieganska et al. 2014). Gatos infectados pelo vírus da imunodeficiência felina apresentam uma flora fúngica mais diversa, o que também pode contribuir para o desenvolvimento de micoses secundárias quando comparados com animais não infectados pelo vírus (Giger \& Smith 2015).

As doenças fúngicas podem afetar uma diversidade de órgãos e apresentar um amplo espectro de sinais clínicos e lesões patológicas (Dial 2007). No estudo, diferentes sinais clínicos foram observados, muitas vezes em decorrência de lesões em mais de um órgão. Além disso, a morfologia das lesões se assemelha a outras enfermidades, levando em alguns casos, a uma suspeita clínica de doenças de maior casuística. Neoplasia foi uma das suspeitas clínicas mais citadas, provavelmente, devido às alterações macroscópicas similares e alta frequência de neoplasmas nessa espécie, principalmente de carcinoma de células escamosas (CCE). Em um estudo de CCE em gatos, as lesões de pele mais comuns eram ulceradas, crostosas, eritematosas e múltiplas, localizavam-se principalmente no nariz, face e orelhas (Favrot et al. 2009), desta forma, são facilmente confundíveis com as lesões descritas em doenças fúngicas.

Os animais de companhia podem ser transmissores de aproximadamente 30 a 40 doenças zoonóticas (Moriello 2003), o que é um fator agravante, principalmente após o avanço da epidemia da AIDS em pessoas, o que fez aumen- tar o caso de zoonoses pouco frequentes nesse grupo da população (Glaser et al. 2015). Estudos indicam que micoses sistêmicas e subcutâneas são as principais causas de morbidade e mortalidade em pessoas imunossuprimidas (Sipsas \& Kontoyiannis 2008).

Nesse trabalho, a doença fúngica mais diagnosticada foi a esporotricose, totalizando $57,63 \%$ dos casos de biópsias e $29,41 \%$ das necropsias de doenças micóticas em gatos no período. Sabe-se que os felinos são altamente suscetíveis a esporotricose e que normalmente o quadro clínico costuma ser grave (Schubach et al. 2015). Outros estudos também indicam uma alta prevalência da doença em gatos quando comparada com outras espécies animais. Em um trabalho que descreve 103 casos de esporotricose, 92 amostras eram provenientes de gatos e 11 eram de cães (Madrid et al. 2012). Em outro estudo com 23 casos de esporotricose, 14 eram de gatos, cinco em equídeos e quatro eram de cães (Crothers et al. 2009). Em outro trabalho, realizado em Pelotas, que descreve diversos casos de doenças em animais domésticos no período de 1978 a 2014, a esporotricose foi responsável por $86 \%$ dos diagnósticos em felinos (Ladeira et al. 2015).

A temperatura ideal de crescimento do Sporothrix schenckii é de 30 a $37^{\circ} \mathrm{C}$ e necessitam também de alta umidade (Barros et al. 2011), o que pode explicar a grande quantidade de casos diagnosticados oriundos da região litorânea do Rio Grande do Sul. Todos os casos apresentados possuíam lesões de pele e dois animais demonstraram disseminação para outros órgãos, com visualização do agente na cavidade nasal, vasos linfáticos e linfonodos. Muitas vezes, a disseminação linfática não é evidente na clínica, e somente é visualizada histologicamente através de biópsias ou após a necropsia (Lloret et al. 2013a).

A lesão microscópica encontrada em todos os casos é típica da doença, que é caracterizada por infiltrado inflamatório piogranulomatoso com eventuais células gigantes multinucleadas e leveduras alongadas, que é altamente sugestivo de esporotricose, em gatos, os micro-organismos são encontrados em grande quantidade (Mauldin \& Peters-Kennedy 2016). Uma característica importante da esporotricose é o seu potencial zoonótico, e o gato é o principal veiculador da doença para os humanos (Montenegro et al. 2014).

Em um estudo realizado pelo Laboratório de Patologia Veterinária da Universidade Federal de Santa Maria, que relata os diagnósticos de micoses e pitioses em animais domésticos em um período de 20 anos, o diagnóstico fúngico mais comum em gatos foi a dermatofitose e criptococose (Galiza et al. 2014).

No presente estudo, entre as micoses sistêmicas, a que apresentou maior frequência foi a criptococose, com a maior casuística na necropsia, totalizando 35,29\%. A criptococose é considerada a principal doença fúngica sistêmica em gatos (Trivedi et al. 2011, Pennisi et al. 2013). Em um estudo retrospectivo realizado na Austrália, que avaliou 195 casos de criptococose, 155 eram em gatos e 40 em cães (O'Brien et al. 2004), o que demonstra a importância da doença em gatos naquele país.

Estudos retrospectivos indicam que a principal localização das lesões é a cavidade nasal, chegando a $75 \%$ das 
apresentações clínicas (Mcgill et al. 2009). No presente estudo, foi constatado, que entre os animais enviados à necropsia e diagnosticados com criptococose, a maioria das lesões foi observada no sistema nervoso central (SNC). Possivelmente, o agente localiza-se na cavidade nasal, porém, pode disseminar-se sistemicamente e chegar ao SNC através da invasão do osso etmoide (Pennisi et al. 2013).

Entre os casos de biópsias, a maioria das lesões se concentrou na pele, o que pode ser sugestivo de disseminação hematógena a partir de outro sítio de infecção (Pennisi et al. 2013).

Na microscopia, a criptococose normalmente apresenta pequena reação inflamatória (Zachary 2012), como foi demonstrado na maioria dos casos deste estudo. Um trabalho que avaliou onze amostras de criptococose cerebral em gatos observou que em nove animais a inflamação era discreta (Sykes et al. 2010). Isso pode ser explicado pela presença da sua cápsula, que possui propriedades que dificultam a fagocitose de macrófagos e neutrófilos e ainda interfere na migração de neutrófilos para os tecidos (Lester et al. 2011).

Nesse trabalho não se obteve diagnóstico de dermatofitose, possivelmente por essa ser uma micose superficial e, na maioria dos casos, seu diagnóstico pode ser estabelecido na clínica, através da lâmpada de Wood ou através do exame tricográfico, ou por cultivo (Moriello 2014) e, muitas vezes, não há necessidade de biópsia. Entretanto, sete casos de pseudomicetoma dermatofítico (PD) foram observados. O PD é uma apresentação atípica da dermatofitose, em que ocorre a formação de múltiplos nódulos subcutâneos (Frymus et al. 2013). Normalmente está associado à infecção por Microsporum canis, e gatos da raça Persa mostram-se predispostos ao desenvolvimento da doença (Chang et al. 2011). Nesse estudo, dos sete casos de PD, seis eram em gatos da raça Persa. Em duas amostras, os nódulos encontravam-se na cavidade abdominal, o que não é comum para a doença, mas pode ocorrer como consequência de laparotomias em animais com dermatofitose cutânea generalizada (Frymus et al. 2013). Em todos os casos a lesão histopatológica foi característica da doença.

A histoplasmose é considerada a segunda micose sistêmica mais importante em felinos (Brömel \& Sykes 2005a), nesse estudo, a histoplasmose apresentou-se como o quarto diagnóstico mais frequente. Normalmente gatos com histoplasmose apresentam pneumonia, doença gastrointestinal e, em algumas situações, doença disseminada progressiva (Lloret et al. 2013b). 0 animal enviado à necropsia apresentava lesões macroscópicas e microscópicas de doença disseminada, pois diversos órgãos foram afetados. Já entre os casos de biopsias, os animais apresentavam lesões de pele e aumento de linfonodos. A alteração macroscópica de pele normalmente está associada com a disseminação do agente (Brilhante et al. 2012), embora um estudo indique que a doença possa ocorrer de forma isolada na pele (Fischer et al. 2013). A histopatologia e citopatologia são os métodos diagnósticos altamente sugestivos de histoplasmose e as lesões em todos os casos foram semelhantes ao descrito em outros trabalhos para a doença, no qual o agente é visualizado predominantemente no interior de macrófagos (Brömel \& Sykes 2005a).
Nesse estudo observou-se dois casos de aspergilose pulmonar. Em gatos, as apresentações mais comuns da aspergilose são a sinonasal e a sino-orbital, e a aspergilose invasiva, que pode envolver os pulmões, ocorre com mais frequência em animais imunodeficientes (Barrs \& Talbot 2014). Nos dois casos de aspergilose observados, os animais apresentavam histórico de diabetes mellitus. Provavelmente o quadro clínico de diabetes contribui para o desenvolvimento da micose, pois animais diabéticos podem apresentar alterações na adesão de neutrófilos, na quimiotaxia e fagocitose dos leucócitos, o que interfe na eficiência da resposta imune inata e favorece à infecções oportunistas (Bieganska et al. 2014).

A feo-hifomicose é considerada rara em gatos (Lloret et al. 2013b, 2013c). Nesse estudo, foi identificado um caso demonstrando que, embora pouco frequente, deve ser considerada como diagnóstico diferencial de outras doenças fúngicas.

Diversos micro-organismos podem causar doença no trato gastrointestinal em gatos, e Candida albicans é um dos principais fungos envolvidos em casos de enterite, normalmente associado com o uso prolongado de antimicrobianos (Pressler 2015).

Nos casos de dermatite fúngica, enterite fúngica, rinite micótica e dermatite e osteomielite fúngica, não foi possível identificar o agente micótico envolvido na lesão e o diagnóstico final foi baseado na alteração morfológica. Muitos fungos podem causar dermatites, porém, no caso demonstrado, as características histomorfológicas são semelhantes às descritas para blastomicose (Brömel \& Sykes 2005b), e este poderia ser um diagnóstico diferencial. Osteomielites fúngicas não são frequentes em gatos, porém os agentes mais comuns são Blastomyces dermatitides, Coccidioides immitis e Cryptococcus neoformans (Craig et al. 2016).

\section{CONCLUSÕES}

Verificou-se que as doenças fúngicas podem ser facilmente confundidas com outras afecções comuns em gatos.

A esporotricose foi o principal diagnóstico obtido entre as micoses de implantação e a criptococose foi a principal infecção micótica sistêmica.

A análise histopatológica e citopatológica é uma importante ferramenta diagnóstica e as colorações especiais de PAS e Grocott auxiliaram na presunção diagnóstica por evidenciar aspectos morfológicos do agente.

\section{REFERÊNCIAS}

Arrington J.B. 1992. Bacteria, fungi, and other microorganisms, p.203-234. In: Prophet E.B., Mills B., Arrington J.B. \& Sobin L.H. (Eds), Laboratory Methods in Histotechnology. American Registry of Pathology, Armed Forces Institute of Pathology, Washington, DC.

Barros M.B.L., Paes R.A. \& Schubach A.O. 2011. Sporothrix schenckii and sporotrichosis. Clin. Microbiol. Rev. 24(4):633-654.

Barrs V.R. \& Talbot J.J. 2014. Feline aspergillosis. Vet. Clin. N. Am., Small Anim. Pract. 44(1):51-73.

Bieganska M., Dardzinska W. \& Dworecka-Kaszak B. 2014. Fungal colonization: an additional risk factor for diseased dogs and cats? Ann. Parasitol. 60(3):139-146.

Brilhante R.S.N., Coelho C.G.V., Sidrim J.J.C., Lima R.A.C., Ribeiro J.F., Cordeiro R.A., Castelo-Branco D.S.C.M., Gomes J.M.F., Simões-Mattos L., Mat- 
tos M.R.F., Beserra H.E.O., Nogueira G.C., Pinheiro A.Q. \& Rocha M.F.G. 2012. Feline histoplasmosis in Brazil: clinical and laboratory aspects and a comparative approach of published reports. Mycopathologia 173(2/3):193-197.

Brömel C. \& Sykes J.E. 2005a. Histoplasmosis in dogs and cats. Clin. Tech. Small Anim. Pract. 20(4):227-232.

Brömel C. \& Sykes J.E. 2005b. Epidemiology, diagnosis, and treatment of blastomycosis in dogs and cats. Clin. Tech. Small Anim. Pract. 20(4):233239.

Chang S.C., Liao J.W., Shyu C.L., Hsu W.L. \& Wong M.L. 2011. Dermatophytic pseudomycetomas in four cats. Vet. Dermatol. 22(2):181-187.

Craig L.E., Dittmer K.E. \& Thompson K.G. 2016. Bones and joints, p.16-163. In: Maxie M.G. (Ed.), Jubb, Kennedy, and Palmer's Pathology of Domestic Animals. Vol.1. 6th ed. Elsevier, St Louis.

Crothers S.L., White S.D., Ihrke P.J. \& Affolter V.K. 2009. Sporotrichosis: a retrospective evaluation of 23 cases seen in northern California (1987/2007). Vet. Dermatol. 20(4):249-259.

Dial S.M. 2007. Fungal diagnostics: current techniques and future trends. Vet. Clin. N. Am., Small Anim. Prac. 37(2):373-392.

Favrot C., Welle M., Heimann M., Godson D.L. \& Guscetti F. 2009. Clinical, histologic, and immunohistochemical analyses of feline squamous cell carcinoma in situ. Vet Pathol. 46(1):25-33.

Fischer N.M., Favrot C., Monod M., Grest P., Rech K. \& Wilhelm S. 2013. A case in Europe of feline histoplasmosis apparently limited to the skin. Vet. Dermatol. 24(6):635-638.

Frymus T., Gruffydd-Jones T., Pennisi M.G., Addie D., Belák S., Boucraut-Baralon C., Egberink H., Hartmann K., Hosie M.J., Lloret A., Lutz H., Marsilio F., Möstl K., Radford A.D., Thiry E., Truyen U. \& Horzinek M.C. 2013. Dermatophytosis in cats abcd guidelines on prevention and management. J. Vet. Intern. Med. 15(7):598-604.

Galiza G.J.N., Silva T.M., Caprioli R.A. Barros C.S.L., Irigoyen L.F., Fighera R.A., Lovato M. \& Kommers G.D. 2014. Ocorrência de micoses e pitiose em animais domésticos: 230 casos. Pesq. Vet. Bras. 34(3):224-232.

Giger U. \& Smith J. 2015. Imunodeficiências e doenças infecciosas, p.11451160. In: Grenne C.E. (Ed.), Doenças Infecciosas em Cães e Gatos. $4^{a}$ ed. Guanabara-Koogan, Rio de Janeiro.

Glaser C.A., Powers E.L. \& Greene C.E. 2015. Infecções zoonóticas de importância clínicas em pessoas imunocomprometidas, p.186-1208. In: Grenne C.E. (Ed.), Doenças Infeciosas em Cães e Gatos. $4^{\mathrm{a}}$ ed. Guanabara-Koogan, Rio de Janeiro.

Gompertz O.F., Gambale W., Paula C.R. \& Corrêa B. 2008. Características gerais das micoses, p.493-502. In: Trabulsi L.R. \& Alterthum F. (Eds), Microbiologia. 5a ed. Atheneu, São Paulo.

Ladeira S.R.L., Ruas J.L., Soares M.P. \& Schild A.L. 2015. Bolim 37 Lab. Regional Diagnóstico. Editora e Gráfica Universitária, Pelotas.

Lester S.L., Malik R., Bartlett K.H. \& Duncan C.G. 2011. Cryptococcosis: update and emergence of Cryptococcus gattii. Vet. Clin. Pathol. 40(1):417.

Lloret A., Hartmann K., Penissi M.G., Ferrer L., Addie D., Belák S., Boucraut-Baralon C., Egberink H., Frymus T., Gruffydd-Jones T., Hossie M.J., Lutz H., Marsilio F., Möstl K., Radford A.D., Thiry E., Truyen U. \& Horzinek M.C. 2013a. Sporotrichosis in cats abcd guidelines on prevention and management. J. Feline Med. Surg. 15(7):619-623.

Lloret A., Hartmann K., Penissi M.G., Ferrer L., Addie D., Belák S., Boucraut-Baralon C., Egberink H., Frymus T., Gruffydd-Jones T., Hossie M.J., Lutz H., Marsilio F., Möstl K., Radford A.D., Thiry E., Truyen U. \& Horzinek M.C. 2013b. Rare systemic mycoses in cats: blastomycosis, histoplasmo- sis and coccidioidomycosis abcd guidelines on prevention and management. J. Feline Med. Surg. 15(7):624-627.

Lloret A., Hartmann K., Penissi M.G., Ferrer L., Addie D., Belák S., Boucraut-Baralon C., Egberink H., Frymus T., Gruffydd-Jones T., Hossie M.J., Lutz H., Marsilio F., Möstl K., Radford A.D., Thiry E., Truyen U. \& Horzinek M.C. 2013c. Rare opportunistic mycoses in cats: phaeohyphomycosis and hyalohyphomycosis abcd guidelines on prevention and management. J. Feline Med. Surg. 15(7):628-630.

Madrid I.M., Mattei A.S., Fernandes C.G., Nobre M.O. \& Meireles M.C.A. 2012. Epidemiological findings and laboratory evaluation of sporotrichosis: a description of 103 cases in cats and dogs in southern Brazil. Mycopathologia 173(4):265-273.

Mauldin E.A. \& Peters-Kennedy J. 2016. Integumentary system, p.509-736. In: Maxie M.G. (Ed.). Jubb, Kennedy, and Palmer's Pathology of Domestic Animals. Vol.1. 6th ed. Elsevier, St Louis.

Mcgill S., Malik R., Saul N., Beetson S., Secombe C., Robertson I. \& Irwin P. 2009. Cryptococcosis in domestic animals in Western Australia: a retrospective study from 1995 to 2006. Med. Mycol. 47(6):625-639.

Montenegro H., Rodrigues A.M., Dias M.A.G., Silva E.A., Bernardi F. \& Camargo Z.P. 2014. Feline sporotrichosis due to Sporothrix brasiliensis: an emerging animal infection in São Paulo, Brazil. BMC Vet. Res. 19(10):269.

Moriello K.A. 2003. Zoonotic skin diseases of dogs and cats. Anim. Health Res. Rev. 4(2):157-168.

O’Brien C.R., Krockenberger M.B., Wigney D.I., Martin P. \& Malik R. 2004. Retrospective study of feline and canine cryptococcosis in Australia from 1981 to 2001: 195 cases. Med. Mycol. 42(5):449-460.

Outerbridge C.A. 2006. Mycologic disorders of the skin. Clin. Tech. Small Anim. Pract. 21(3):128-134.

Pennisi M.G., Hartmann K., Lloret A., Ferrer L., Addie D., Belák S., Boucraut-Baralon C., Egberink H., Frymus T., Gruffydd-Jones T., Hossie M.J., Lutz H., Marsilio F., Möstl K., Radford A.D., Thiry E., Truyen U. \& Horzinek M.C. 2013. Cryptococcosis in cats abcd guidelines on prevention and management. J. Feline Med. Surg. 15(7):611-618.

Pressler B.M. 2015. Candidíase e rodotorulose, p.700-706. In: Greene C.E. (Ed.), Doenças Infecciosas em Cães e Gatos. 4르 ed. Guanabara Koogan, Rio de Janeiro.

Quinn P.J., Markey B.K., Leonard F.C., FitzPatrick E.S., Fanning S. \& Hartigan P.J. 2011. General features of fungi associated with disease in animals, p.413-418. In: Quinn P.J., Markey B.K., Leonard F.C., FitzPatrick E.S., Fanning S. \& Hartigan P.J. (Eds), Veterinary Microbiology and Microbial Disease. 2nd ed. Wiley-Blackwell, Ames.

Sipsas N.V. \& Kontoyiannis D.P. 2008. Occupation, lifestyle, diet, and invasive fungal infections. Infection 36(6):515-525.

Schubach T.M.P., Menezes R.C. \& Wanke B. 2015. Esporotricose, p.678-684. In: Greene C.E. (Ed.), Doenças Infecciosas em Cães e Gatos. 4ª ed. Guanabara Koogan, Rio de Janeiro.

Sykes J.E., Sturges B.K., Cannon M.S., Gericota B., Higgins R.J., Trivedi S.R., Dickinson P.J., Vernaus K.M., Meyer W. \& Wisner E.R. 2010. Clinical signs, imaging features, neuropathology, and outcome in cats and dogs with central nervous system cryptococcosis from California. J. Vet. Intern. Med. 24(6):1427-1438.

Trivedi S.R., Malik R., Meyer W. \& Sykes J.E. 2011. Feline cryptococcosis impacto of current research on clinical management. J. Feline Med. Surg. 13(3):163-172.

Zachary J.F. 2012. Nervous system, p.771-870. In: McGavin M.D. \& Zachary J.F. (Eds), Pathologic Basis of Veterinary Disease. 5th ed. Elsevier Mosby, St Louis. 